\title{
IMPROVING OIL CONTAMINATED SOIL CHARACTERISTICS THROUGH THE USE OF COMBINED TREATMENTS NECESSARY FOR PHYTOREMEDIATION TECHNOLOGIES
}

\author{
Smaranda Masu ${ }^{1}$, Florica Morariu ${ }^{2}$ \\ ${ }^{1}$ INCD-ECOIND, Branch of Timisoara, 300004, 1 Regina Maria Square, Timisoara, \\ emailsmarandamasu@yahoo.com, Romania \\ ${ }^{2}$ Banat's University of Agricultural Sciences and Veterinary Medicine "King Michael I of \\ Romania", Department of Biotechnologies, 117 Calea Aradului, Timisoara, Romania
}

\begin{abstract}
The objective of this study was to determine the possibility of using fly ash amendment optimal doses from a thermal plant, mixed with a fertilizer agent, anaerobically stabilized sewage sludge to reduce stress caused by the presence of large amounts of $113.5 \mathrm{~g} \cdot \mathrm{kg}^{-1}$ D.M. of oil product, TPH, (Total Petroleum Hydrocarbons) in polluted soils. The study was conducted in vegetation pots to determine the emergence degree and development of a culture of forage leguminous plants of Lotus corniculatus species, bird's foot trefoil. The experimental variants were treated with fly ash and fertilized with $500 \mathrm{~g}$ per vegetation pot of anaerobically stabilized sewage sludge. Studies were done in comparison with experimental versions cultivated with bird's foot trefoil of polluted soil treated with fly ash, polluted soil fertilized untreated with ash. The addition of fertilizing agent mixed with small amount of fly ash caused a emergence degree of $50-60 \%$, and the reduction of the content of oil product, after 4 months of vegetation, by $29.9 \%$. The maintaining of vegetation in perennial regime specific to this plant species demonstrates the plant tolerance to conditions created by the treatment of polluted soil with adequate amounts of fertilizer and fly ash amendment,
\end{abstract}

Keywords: bird's foot trefoil, fly ash, phytoremediation, sewage sludge, total petroleum hydrocarbons,

\section{Introduction}

The aim of the study is to investigate Total Petroleum Hydrocarbons (TPH) contaminated soil vegetation of forage leguminous plants of birdsfoot trefoil species (Lotus corniculatus). TPH contaminated areas were previously treated with fly ash to reduce the aggressive character of pollutants. In addition, sewage sludge anaerobically stabilized fertilizer was added to complete the necessary soil nutrients.

Because phytoremediation is an emerging technology, standard performance criteria for phytoremediation systems have not yet been established, and performance must be determined based on the results. Phytoremediation is a low input approach depending on natural attenuation by biodegradation and physiochemical mechanisms that decrease the pollutant concentration wherein sowing plants may be the only intervention [1-2]. Plant species, such leguminous, can be used in the remediation of contaminants in surface soil. To evaluate the performance of phytoremediation, the concentrations of soil 
contaminants and removal efficiencies should be measured. Monitoring should be conducted for soil and aerial part of plant and root characteristics. Rigorous performance evaluation will help demonstrate the system's ability to meet cleanup goals. Because phytoremediation is an emerging technology, standard performance criteria for phytoremediation systems have not yet been established, and performance must be determined based on the results [3-5]. Long term monitoring is necessary for phytoremediation systems that require long time horizons to demonstrate their continued effectiveness. Monitoring may be continued after short-term cleanup goals have been met to determine the impact of the phytoremediation system on the ecosystem. These treatments, though effective, are costly and involve inexpensive site disturbance [6-9].

\section{Materials and Methods}

The experimental study was done in the experimental block. Soil tested $(6.5 \mathrm{~kg})$ was added in each pot. A filter paper was placed in the bottom of each pot to prevent the dry soil escaping out from the drainage holes and pots were placed on saucers. The soil was polluted with TPH $113.5 \pm 3.90 \mathrm{~g} \cdot \mathrm{kg}^{-1} \mathrm{D} . \mathrm{M}$. and was taken from an area related to oil extraction activities or a park of oil drilling probes. Soil pollution began with oil extraction activities in the area. The area was polluted with because of accidental leaks, malfunctions, etc. Stress due to pollutants for sprouting seed and seedling was diminished through the addition of fly ash from power plants. Polluted soil fertilization was performed with anaerobically stabilized sewage sludge taken from a municipal wastewater treatment plant. Experimental variants of soil cultivated with bird's foot trefoil. The control version was the TPH contaminated soil untreated and uncultivated, it was M. Each experimental variant contains three replicas. The plants used for phytoremediation of soils heavily contaminated with TPH were from the Lotus corniculatus species. The amount of petroleum products from soils was determined by the standard Romanian method presented by Masu et al., 2014 [10]. Experimental variants studied are presented in Table 1.

Table1. Experimental variants from bird's foot trefoil (Lotus corniculatus) block.

\begin{tabular}{|c|c|c|c|c|c|c|}
\hline \multirow{2}{*}{$\begin{array}{l}\text { TPH } \\
\text { polluted } \\
\text { soil } \\
\text { treatment }\end{array}$} & \multicolumn{6}{|c|}{ Experimental variants } \\
\hline & M & PB & PC 1 & PC 2 & BC 1 & BC 2 \\
\hline $\begin{array}{l}\text { sewage } \\
\text { sludge }\end{array}$ & untreated & $\begin{array}{c}50 \mathrm{t} . \mathrm{ha}^{-1} \\
(500 \mathrm{~g} / \mathrm{pot})\end{array}$ & & $\begin{array}{c}\text { 50t.ha- } \\
\text { (500g/pot) }\end{array}$ & $\begin{array}{c}\text { 50t.ha } \\
\text { (500g/pot) }\end{array}$ & $\begin{array}{c}50 \mathrm{t} . \mathrm{ha}^{-1} \\
(500 \mathrm{~g} / \mathrm{pot})\end{array}$ \\
\hline fly ash & untreated & & $\begin{array}{c}50 \mathrm{tha}^{-1} \\
(500 \mathrm{~g} / \mathrm{pot})\end{array}$ & $\begin{array}{c}50 \mathrm{t} \cdot \mathrm{ha}^{-1} \\
(500 \mathrm{~g} / \mathrm{pot})\end{array}$ & $\begin{array}{c}\text { 25t.ha- } \\
(250 \mathrm{~g} / \mathrm{pot})\end{array}$ & $\begin{array}{l}5 t . \mathrm{ha}^{-1} \\
(50 \mathrm{~g} / \mathrm{pot})\end{array}$ \\
\hline $\begin{array}{c}\text { plants } \\
\text { species }\end{array}$ & $\begin{array}{c}\text { Uncultivate } \\
d\end{array}$ & Lotus sp. & Lotus $s p$. & Lotus $s p$ & Lotus sp. & Lotus sp. \\
\hline
\end{tabular}




\section{Results and Discussion}

Table 2 show the seedling degrees, coverage degrees, aerial part and root length from the experimental variants after four month. For the variants treated with $500 \mathrm{~g}$ sludge/vegetation pot and different amounts of ash 500,250 and $50 \mathrm{~g}$ /vegetation pot is observed that using the minimum amount of fly ash generated a high degree of seedling and subsequently high level of plant development compared to the variants for which the added fly ash amount was great. Plants grown in the variant treated with sewage sludge in a quantity of $500 \mathrm{~g}$ sludge/vegetation pot and fly ash in quantity of $50 \mathrm{~g} / \mathrm{vegetation}$ pot (sewage sludge : ash ratio $=10: 1$ ) were more vigorous, developed more ramifications, longer in their ramifications compared to the plants grown on the other two variants. The plants had vigorous roots with greater length. Coverage degree of the sown area after 4 months of vegetation was two times higher in the variant treated with $500 \mathrm{~g} / \mathrm{vegetation}$ pot and a small amount of fly ash compared to the variants treated with high amounts of fly ash $250 \mathrm{~g}$ and $500 \mathrm{~g} / \mathrm{vegetation}$ pot, respectively.

Table 2. Physiological characteristics of plants from the experimental block equipped with soil which contained $113.5 \cdot \mathrm{kg}^{-1}$ D.M. of oil products

(TPH).

\begin{tabular}{|c|c|c|c|c|c|c|}
\hline Parameters & \multicolumn{5}{|c|}{ Experimental variants } \\
\cline { 2 - 7 } & M & PB & PC 1 & PC 2 & BC 1 & BC 2 \\
\hline $\begin{array}{c}\text { Seedling } \\
\text { degree [\%] }\end{array}$ & $\begin{array}{c}\text { Few } \\
\text { plants }\end{array}$ & $\begin{array}{c}\text { Few } \\
\text { plants }\end{array}$ & $25-30$ & $40-50$ & $50-60$ \\
\hline $\begin{array}{c}\text { Coverage after } \\
\text { four month [\%] }\end{array}$ & $\begin{array}{c}5-6 \\
\text { plants }\end{array}$ & $\begin{array}{c}5-6 \\
\text { plants }\end{array}$ & $15-27$ & $25-35$ & $50-55$ \\
\hline $\begin{array}{c}\text { Stem length } \\
\text { after four } \\
\text { month [cm] }\end{array}$ & $\begin{array}{c}5-7 \mathrm{~cm} \\
\text { dried } \\
\text { plants }\end{array}$ & $\begin{array}{c}\text { Plants } \\
\text { dried }\end{array}$ & $\begin{array}{c}8-15 \mathrm{~cm} \text { with } \\
1-3 \\
\text { ramifications }\end{array}$ & $\begin{array}{c}18-30 \mathrm{~cm} \text { with } \\
5-6\end{array}$ & $\begin{array}{c}28-30 \mathrm{~cm} \text { with } \\
\text { ramifications } \\
\text { ramifications }\end{array}$ \\
\hline $\begin{array}{c}\text { Root length } \\
\text { after four } \\
\text { month [cm] }\end{array}$ & & & & $\begin{array}{c}3 \mathrm{~cm} \\
\text { pivoting root }\end{array}$ & $\begin{array}{c}5 \mathrm{~cm} \\
\text { pivoting root }\end{array}$ & pivoting root \\
\hline
\end{tabular}

Table 3 shows the variations of TPH content from the experimental variants of the studied soil cultivated with bird's foot trefoil during the monitored period.

Table 3. Variations of TPH content from the experimental variants of the studied soil cultivated with bird's foot trefoil during the monitored period

\begin{tabular}{|c|c|c|c|c|c|c|c|}
\hline \multirow[t]{2}{*}{ No } & \multirow{2}{*}{$\begin{array}{l}\text { Rezidual TPH from } \\
\text { experimental variants }\end{array}$} & \multicolumn{6}{|c|}{ Experimental variants } \\
\hline & & $\mathrm{M}^{*}$ & PB & PC1 & PC2 & $\mathrm{BC} 1$ & $\mathrm{BC} 2$ \\
\hline 1 & $\begin{array}{l}\text { after two } \\
{\left[\mathrm{g} \cdot \mathrm{kg}^{-1} \text { D.M. }\right]}\end{array}$ & 98.8 & 95.4 & 109.4 & 94.5 & 85.2 & 89.6 \\
\hline 2 & $\begin{array}{l}\text { after four month } \\
{\left[g \cdot \mathrm{kg}^{-1} \text { D.M. }\right]}\end{array}$ & 93.7 & 94.0 & 106.3 & 90.2 & 83.5 & 79.5 \\
\hline
\end{tabular}

*non cultivate 
Figure 1 shows the reduction efficiencies of TPH from the experimental variants from the soil cultivated with bird's foot trefoil from the experimental block during the monitored period. The initial concentration of TPH from the soil was $113.5 \mathrm{~g}$. $\mathrm{kg}^{-1}$ D.M.

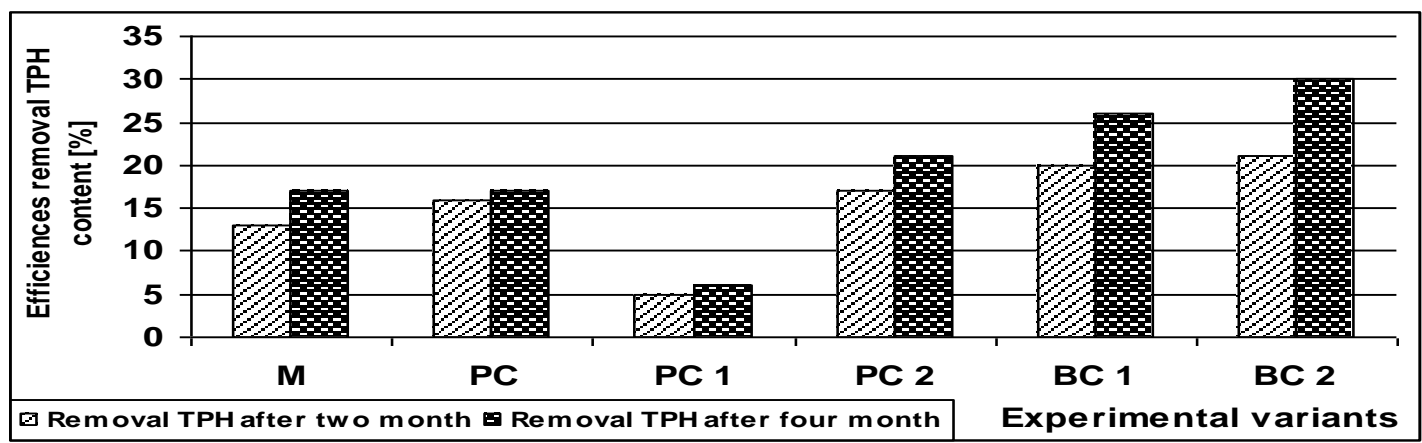

Figure. 1 Efficiencies the reduction of TPH from the experimental variants from the soil cultivated with bird's foot trefoil from the experimental block during the monitored period

It is noted from Table 3 and Figure 1 that the experimental variant of polluted soil treated with fly ash in which crop dries prematurely the TPH reduction efficiency is insignificant. Perhaps the fly ash through absorption phenomena retains petroleum products and does not allow their volatilization. Observe in Figure 1 that the treated sludge variants the loss of petroleum products in the soil was slightly higher than in the variants of unfertilized soils. With a dose of $500 \mathrm{~g}$ sludge used as fertilizer for one vegetation pot equipped with polluted soil is needed the optimal dose of fly ash of $50 \mathrm{~g} / \mathrm{vegetation}$ pot (namely a sludge : ash ratio of $10: 1$ ) to obtain the cultures that contribute to obtain the high efficiencies of removal of TPH. TPH removal efficiencies were for the optimal variant of treatment of soil polluted with TPH and planted with bird's foot trefoil up to $30 \%$ in the monitored period.

\section{Conclusions}

In the case of a soil polluted with $113.5 \mathrm{~g} \cdot \mathrm{kg}^{-1}$ D.M. of petroleum products, TPH for the optimal variant of bird's foot trefoil culture was necessary the addition of $500 \mathrm{~g} /$ vegetation pot fertilizing agent in mixture with small amounts of ash $50 \mathrm{~g} /$ vegetation pot (ratio sludge : ash $=10: 1$ parts weight). The results were: germination degree of $50-60 \%$ and coverage of $50-55 \%$ of the cultivated area. Plants reach normal height and vigorous and well developed roots; reduction efficiency of TPH content after 4 months of growing by $29.9 \%$. In the other variants in which the amount of sludge related to the quantities of ash was lower by 1.1 respectively $2: 1$, hydrocarbons petroleum hydrocarbons biodegradation rates were slower than the optimal variant for which a large excess of sludge was used. The ash removal efficiencies of TPH were in the range of $21-26 \%$ in the monitored period of four months for the addition of large amounts of fly ash in the fertilizer. The use of fly ash and biodegradable waste sewage sludge led to the settling of a stable and healthy vegetation cover over a short period of time. 


\section{Acknowledgements}

The research given the Ministry of Education Research, Youth and Sports which provide financial support for Nucleu Program PN 09-13 03 07. Thank are due to: Prof. Nicolae Dragomir Banat s University Agricultural Sciences and Veterinary of Medicine, Timisoara, Romania

\section{References}

1. Liu R., Jadeja N, R., Zhou Q., Liu Z., (2012), Treatment and Remediation of Petroleum-Contaminated Soils Using Selective Ornamental Plants, Environmental Engineering, 29 (6), 494-501.

2. Dumitru M., Constantin C., Ivana C., (2003), .PAH content in soil Moldova Noua- Orsova area, Journal of Environmental Protection and Ecology, 4 (4), 783-786.

3. ${ }^{*}$ US Environmental Protection Agency. 2001, Office of Solid Waste and Emergency Response, Technology Innovation Office, Brownfield's Technology: Selecting and Using Phytoremediation for Site Cleanup,. Washington DC, USA.

4. Halbac R., Cotoroaga Z., (2012), The Romanian Banat Region Challenging Climatic Changes Journal of Environmental Protection and Ecology, 13 (1), 128-133.

5. Baghina I., Radulov I., Berbecea A., Moisuc A., Stroia C., (2014), Sewage sludge fertilization influence on main soil chemical features, Journal of Environmental Protection and Ecology, 15(1), 217-222.

6. Babeanu C., Basea E., Marinescu G., Ciobanu G., (2003), Investigation on bio fertilizer effect of humic acids by comparison with other synthetic and biological fertilizers, Journal of Environmental Protection and Ecology, 4 (2), 386-392.

7. Abiven S., Menasseri, S., Chenu C,. (2009). The effects of organic inputs over time on soil aggregate stability. A literature analysis, Soil Biology and Biochemistry, 41(1), 1-12.

8. Bona C., de Rezende J.M., de Oliveira Santos G., de Souza I.A., (2011), Effect of soil contaminated by diesel oil on the germination of seeds and the growth of Schinus terebinthifolius Raddi (Anacardiaceae) Seedlings, Brazilian Archive Biological Technology, 54 (6), 1379-1387.

9. Masu S., Rus V., (2013). Studies Regarding the Establishment of Perennial Plant Communities Stimulated with Biosolids on Fly Ash Dumps, Journal of Environmental Protection and Ecology, 14(1), 204-206.

10.Masu S., Albulescu M., Bălăsescu L.C., (2014), Assessment on Phytoremediation of Crude Oil Polluted Soils with Achillea millefolium and Total Petroleum Hydrocarbons Removal Efficiency, Revista de. Chimie, 65(9), 1103-1107. 